\title{
Health Behaviour and Health Assessment: Evidence from German Microdata
}

\author{
Brit S. Schneider and Udo Schneider \\ Department of Law and Economics, Institute of Public Finance, University of Bayreuth, 95440 Bayreuth, Germany \\ Correspondence should be addressed to Udo Schneider, udo.schneider@uni-bayreuth.de
}

Received 31 August 2011; Revised 3 November 2011; Accepted 4 November 2011

Academic Editor: Almas Heshmati

Copyright ( $) 2012$ B. S. Schneider and U. Schneider. This is an open access article distributed under the Creative Commons Attribution License, which permits unrestricted use, distribution, and reproduction in any medium, provided the original work is properly cited.

\begin{abstract}
The importance of the individual's health behaviour for the health production process is beyond controversy. Health relevant behaviour can be viewed as a key variable in the health production process. Changes in the behaviour may influence individual's assessment of health. Following this idea, we use German microdata to identify determinants of smoking, drinking, and obesity and their impact on health. Our empirical approach allows for the simultaneity of behaviours and self-reported health. In addition, we account for endogeneity of health behaviours and take aspects of reporting heterogeneity of self-reported health into account. We find that health behaviour is directly related to the socioeconomic status and observe gender-specific differences in the determinants of drinking, smoking, and heavy body weight in particular. The influence on health is also gender specific. While we do not find any impact of smoking, overweight is relevant only for males and no clear pattern for alcohol exists.
\end{abstract}

\section{Introduction}

Unhealthy behaviours like smoking, alcohol abuse, malnutrition, or lack of exercise are known causes of chronic health conditions [1]. Diseases like cardiovascular diseases, respiratory diseases, or several types of cancer are directly linked with tobacco consumption, going along with higher mortality [2]. While the health effects of smoking are almost linked to long-term consumption, alcohol abuse also is related to acute consequences. Besides chronic diseases like cancer, diabetes mellitus, cardiovascular diseases, or neuropsychiatric health disorders, drinking goes along with an increased risk of injury or accidents [3]. High-calorie intake, and lack of exercise are main reasons for high body weight and obesity $^{1}$ causing coronary heart disease, hypertension, diabetes mellitus, and certain types of cancer as well as osteoarthritis [4]. Sturm [5] estimates that obesity promotes chronic health conditions in the same way as 20 years' aging does.

Taking the high number of chronic diseases as well as the risk of acute consequences of adverse health behaviour into account, these can be directly related to high economic costs due to hospital stays, medical and pharmaceutical consumption. Moreover, as this often goes along with inability to work, indirect economic costs like foregone earnings because of lost productivity also have to be calculated. Beginning with the annual costs of smoking, estimations for the United States show that annual economic costs attributable to smoking were $\$ 157.7$ billion, where $\$ 75.5$ billion are paid for direct medical care and \$ 366 million for neonatal care. Lost productivity sums up to a total value of $\$ 81.9$ billion. For the United States, tobacco-related deaths sum up to 440,000 per year, resulting in more than 5.6 million years of potential life lost (YPLL) [2]. Again for the United States, Sturm [5] estimates an increase in costs for in-patient and ambulatory care. Here, the effect for current or ever smoking sums up to about \$230 per year for each individual. Due to the aging effect of smoking, health care costs increase about 20 percent and medication costs increase about 105 percent. Harwood [6] calculates the economic costs for alcohol abuse. For the US, costs of heavy drinking are estimated to \$ 185 billion in 1998. While the medical consequences of alcohol are comparably low (nearly $\$ 18.9$ billion), it leads to lost earnings due to premature deaths ( $\$ 36.5$ billion) and to lost productivity due to morbidity amounting to $\$ 87.6$ billion. Finkelstein et al. [7] estimate rising per capita medical spending in the United States due to a higher prevalence of 
obesity. Compared to normal-weight individuals, spending was $\$ 1,429$ or 42 percent higher in 2006. 8.5 percent of Medicare spending, 11.8 percent of Medicaid spending, and 12.9 percent of out of pocket spending are related to obesity with increasing tendency.

As we use German microdata from the Socio-Economic Panel in our analysis, health care costs in Germany which are attributable to adverse health behaviour are also of interest. Referring to the health effects of smoking in Germany, 114,647 deaths can be directly related to tobacco consumption in 2003, leading to 1.6 million YPLL. Total costs sum up to $€ 21.0$ billion, where $€ 7.5$ billion are attributable to care and prescribed drugs. $€ 8.8$ billion are indirect costs due to foregone income and $€ 4.7$ billion are indirect costs of mortality [8].

Nearly 5.5 percent of all deaths (970,000 YPLL) were related to alcohol consumption [9]. Total costs were estimated at $€ 24.4$ billion, amounting to 1.16 percent of Germany's GDP, or $€ 296$ per person, splitting in direct costs of $€ 8.4$ billion and indirect costs of nearly $€ 16$ billion, whereas 69 percent were related to mortality and 31 percent to morbidity. While excessive alcohol consumption leads to severe diseases, moderate consumption can also have protective health effects. These are related to savings up to $€ 4.8$ billion.

Konnopka et al. [10] estimated cost effects of obesity for Germany, using data from 2002. In their analysis, 36,653 deaths were attributable to obesity and overweight, resulting in 428,093 years of potential life lost. $€ 4.8$ billion had to be paid for health care services and rehabilitation, corresponding to 2.1 percent of the overall German health expenditures in 2002. Indirect costs, covering costs of sickness absence, early retirement and mortality, were estimated at $€ 5$ billion.

Taking economic costs into account, it seems clear that prevention may be an effective instrument to release individuals from suffering and to save health expenditures. For prevention policies to be effective, individuals have to perceive adverse health effects of excessive drinking, smoking, or overweight. Furthermore, knowledge about the determinants of health-related behaviour is essential. For example, health politics generally tries to implement personal responsibility through financial incentives using demand side costsharing rules. This first implies that we face a lack of patients' responsibility rather than missing abilities to handle the own health capital stock. Second, health behaviour must be related to income. Otherwise, financial incentives would be inefficient.

In the literature, there exists broad empirical research on health behaviour and individual health, but, to our knowledge, these studies do not take possible causes for adverse health behaviour into account. Furthermore, most studies only focus on a single behaviour. In order to close this gap, we apply a simultaneous equations model on adverse health factors (smoking, drinking, and obesity) and health.

In detail, our empirical approach uses self-reported health as a measure of the individual health capital stock. In addition and in contrast to other studies, we take the probability of reporting heterogeneity in self-assessed health into account. Here, literature has shown that answers to the assessment of individual health may depend on personal characteristics like age, education, income, or the utilisation of medical resources [11]. Moreover, to take care of gender differences in health behaviour, we analyse the relation between behaviour and health assessment separately for women and men.

\section{On the Relationship between Health-Related Behaviour and Health}

From a theoretical perspective, health behaviour can be treated as investment in health, leading to a high health capital stock. The necessity of investing in health results from the idea that health underlies an age-dependent depreciation rate [12]. Besides direct utility aspects of a good health status, productivity is higher and illness rates and therefore absence from work are lower. This approach of Grossman is enhanced by the consideration that health depreciation might not only be a consequence of aging but could also be related to adverse health behaviour. Hence, the effects of health behaviours are twofold: besides any utility aspects, smoking, heavy drinking, being overweight, or even obese may be relevant depreciation factors, whereas nonsmoking, no or moderately drinking, and body weight in a normal range may be seen as (the consequences of) health investments.

The channels through which health-related behaviours affect health are diverse, and it is of main interest which factors determine adverse health behaviour. Obesity, for instance, is known as a central risk factor for health. The most severe diseases related to heavy body weight are "hypertension and hyperlipidaemia (major risk factors), coronary heart disease, ischaemic stroke, type 2 diabetes, certain types of cancer, osteoporosis, and psychosocial problems" [4], among others. Smoking is associated with an increase in the risk of death due to a higher risk of cardiovascular diseases and lung and oral cancer [13, 14]. For cardiovascular diseases, a combination of obesity and smoking leads to even higher health risks [15].

The effects of alcohol consumption on health are somewhat ambiguous. Several studies show that low alcohol intake is inversely related to coronary heart disease, whereas alcohol abuse is responsible for an increased risk of cirrhosis and several types of cancer. Therefore, the relationship between alcohol consumption and (ill) health is often depicted as a J-shaped curve, with higher mortality rates for nondrinkers and heavy drinkers (for an overview, see $[16,17]$ ).

Given the harmful health consequences of adverse health behaviours like smoking and heavy drinking or fast food consumption and lack of exercise as possible reasons for overweight or obesity, theory suggests that there are a lot of impact factors on health behaviour and health, for example, education, the relative income position of an individual household, the socioeconomic status as a whole, and labour force participation.

In general, education yields better health knowledge which is important to understand the health effects of one's actions. For instance, better educated individuals should know more about the long-term health risks of overweight; so it can be expected that they pay more attention to their 
nutrition in order to watch their weight. In addition, one can assume that better educated people know about the hazardous consequences of smoking. Kenkel [18], for instance, shows that education has a significant negative impact on smoking and alcohol drinking, while the impact on doing sports is significantly positive. Moreover, education is highly correlated with labour income leading to high opportunity costs of illness. Last, the efficiency of the health production is also determined through the individual's education level, first because of an efficient allocation of medical services and second because of the knowledge how to use them correctly [19].

Labour force participation should be considered as another important factor on health relevant behaviour. First, long working hours reduce leisure time and health investment activities. There is less time disposable for recreation, doing sports, or even consuming some health services for preventive purposes. Second, the kind of work is decisive for its health depreciation rate $[20,21]$. On the one hand, people like blue collar workers with physically exhausting jobs may be less willing or less able to exercise after work. On the other hand, managers mostly have stressful jobs with long working hours. To cope with high stress levels, they may face a high risk of being a smoker, drinking alcohol, or having excess weight $[13,22,23]$. Third, working conditions and education both determine earned income, which is itself fundamental for health-related behaviour. Low-income individuals, for example, tend to consume cheaper meals with low nutritional value. As a consequence, the risk of overweight or even obesity is much higher at low incomes [24].

Apart from these three direct effects of labour force participation on health relevant behaviour, opportunity costs of illness rise with labour income, which means that illness reduces current and future earnings. Because of this, the benefits of healthful activities are largest for well-educated people with high labour income $[25,26] .^{2}$ Unemployed face lower opportunity costs as being ill is not directly related to actual income but reduces the chances of returning into the labour force. As a consequence, economic incentives for health investment activities are lower. Mathers and Schofield [27] show, for instance, that besides a poorer mental health, those who are unemployed have greater odds of suffering chronic illnesses. There is also some evidence that unemployed people tend towards higher levels of smoking, alcohol use, and poor diet.

The effects of different lifestyles on health are analysed by Lin [28]. Using data from Taiwan, he estimates the impact of smoking, drinking, exercise, and a high BMI on self-assessed health and finds that individuals with healthier lifestyles tend to have better self-assessed health. Using the ordinal structure of self-assessed health, he runs ordered probit regressions with health behaviours as explanatory factors thereby neglecting possible endogeneity. Balia and Jones [29] estimate the influence of selected health behaviours on health and subsequent mortality using a multivariate probit model. They find that nonsmoking, regular breakfast, and sleeping reduce mortality but have no impact on self-assessment of health while the effects of obesity and exercise are reversed.

\section{Data}

Regarding these findings, the relation between individual behaviour and health is of simultaneous nature. The different forms and consequences of health relevant behaviour, for example, smoking, drinking, or obesity, are health risk factors on their own, but the magnitude of the health impact rises if two or more behavioural patterns are present [15]. To estimate the dependence of health on behaviour, we use data from the German Socio-Economic Panel (SOEP), a representative longitudinal study of private households in Germany where all adult household members are surveyed. ${ }^{3}$ Hence, individuals are the underlying measurement unit; only income is based on household information. Explicitly, we focus on the year 2006 where different variables concerning health status and health behaviour are included, namely, smoking and alcohol consumption. Furthermore, the BMI is incorporated in the dataset. ${ }^{4}$ As commonly used, we take a $\mathrm{BMI} \geq 30$ as a binary measure of obesity [30]. While one can argue that being overweight is not a health behaviour, it is a function of nutritional intake and exercise and hence a proxy for both kinds of behaviour. Individual health is included as a self-reported variable with five categories.

All four variables of interest are binary or categorical ones. Hence, a simultaneous model for qualitative dependent variables is used. Among this class of models, the multivariate probit model allows for a recursive structure, for example, that the behaviour variables directly enter the health equation. Moreover, the estimation approach accounts for a possible correlation of the residuals. With respect to this estimation strategy, all dependent variables have to be transformed into binary variables. A dichotomous variable indicating whether the respondent currently smokes is provided. While there is evidence that smoking more than 20 cigarettes per day increases the risk of cardiovascular diseases dramatically, one has to keep in mind that smoking per se increases the risk of several forms of cancer and respiratory diseases [5]. Therefore, we use the binary indicator of current smoking to account for the various health effects. The frequency of alcohol consumption is measured by the four categories regularly, occasionally, seldom, and never. Because of the anticipated J-shape of alcohol consumption on health, we focus on the highest category of drinking; so the variable alcohol takes the value 1 if the respondent drinks at least one of the following beverages regularly: beer, wine or champagne, spirits, or mixed drinks.

The self-assessed health variable in the dataset might be vulnerable to reporting heterogeneity. For the correction of self-assessed health, questions that rely on the so-called SF$12 \mathrm{v} 2$ indicators [31] are used to compute a new health stock variable which takes the value 1 if health is assessed above average and 0 otherwise (see chapter 4$).^{5}$

The independent variables can be divided into predisposing and socioeconomic variables (see Table 1). First, four age categories capture the deterioration of health with age due to comorbidity risks. In addition, partnership and children are indicators for the family structure of the respondent. Behavioural differences between Eastern and Western Germans are of interest as well as differences to foreigners. 
TABLE 1: Description of the variables.

\begin{tabular}{|c|c|}
\hline \multicolumn{2}{|l|}{ Endogenous variables } \\
\hline Smoker & Tobacco consumption yes/no \\
\hline Alcohol & Drinks alcohol regularly yes/no \\
\hline Obesity & Overweight in terms of age-adjusted BMI yes/no \\
\hline Health & Self-assessed health above-average \\
\hline \multicolumn{2}{|l|}{ Predisposing variables } \\
\hline Age 17-29 & Respondent 17 to 29 years old yes/no (reference group) \\
\hline Age $30-44$ & Respondent 30 to 44 years old yes/no \\
\hline Age $45-59$ & Respondent 45 to 59 years old yes/no \\
\hline Age $60-74$ & Respondent 60 to 74 years old yes/no \\
\hline Age $>74$ & Respondent older than 74 years yes/no \\
\hline Partnership & Living together with a partner yes/no \\
\hline Children & At least one child younger than 16 years in household yes/no \\
\hline Eastern Germany & Living in Eastern Germany yes/no \\
\hline Turkey & Nationality Turkish yes/no \\
\hline Rest of World & Other nationality not German yes/no \\
\hline \multicolumn{2}{|l|}{ Socioeconomic variables } \\
\hline Rel. poverty & Less than $50 \%$ of the mean of equivalent household net income $(<€ 797.50)$ \\
\hline Tenous prosperity & $50-75 \%$ of the mean of equivalent household net income $(€ 797.50-€ 1,196.25)$ \\
\hline Middle income position & $75-125 \%$ of the mean of equivalent household net income (reference group; $€ 1,196.25-€ 1,993.75$ ) \\
\hline Higher income & $125-150 \%$ of the mean of equivalent household net income $(€ 1,993.75-€ 2,938.50)$ \\
\hline Rel. prosperity & More than $150 \%$ of the mean of equivalent household net income $(>€ 2,938.50)$ \\
\hline Economic worries & Strong worries about own economic situation yes/no \\
\hline Retired & Retired yes/no \\
\hline Unemployed & Long-term unemployment in 2005 and unemployed at the time the survey was conducted in 2006 yes/no \\
\hline Working h. 1-21 & 1-21 hours effectively worked per week yes/no \\
\hline Working h. 22-42 & 22-42 hours effectively worked per week yes/no \\
\hline Working h. $>42$ & More than 42 hours effectively worked per week yes/no \\
\hline Secondary school & Secondary school degree or no completed education (reference group) \\
\hline O-level & First public examination in secondary school yes/no \\
\hline High school & General qualification for university entrance yes/no \\
\hline University & University degree yes/no \\
\hline Education & Currently in some sort of education yes/no \\
\hline Private health ins. & Fully private insured yes/no \\
\hline Supplemental ins. & Private supplemental health insurance yes/no \\
\hline Risk averse & Respondent is risk averse yes/no \\
\hline Risk taker & Respondent is risk taker yes/no \\
\hline Renovation & House is at least partly in need of renovation yes/no \\
\hline Mother O-level & Mother at least O-Level education yes/no \\
\hline Father O-level & Father at least O-Level education yes/no \\
\hline
\end{tabular}

Second, socioeconomic variables are included to explain the economic environment. The first variables in this category, namely, income, economic worries, and unemployment, determine the money disposable for consumer and health care goods. First, the net household equivalent income is computed. In a second step, five income categories are built to account for differences in the relative income position of the households [32]. The income position is based on a percentage of the mean of the net household equivalent income which is at about $€ 1,595$.

Furthermore, working hours are used to explain the trade-off between work, health investment, and leisure, and to control for working conditions. ${ }^{6}$ To control for the expected nonlinear effects, dummy variables for different classes of working hours are created. Furthermore, we include dummy variables indicating whether a respondent is retired or longterm unemployed. Our reference group are those individuals who do not work, are not retired, and are not registered as unemployed.

We are also interested in possible effects of education on health behaviour and health. Therefore, four education variables as well as two variables containing information about the educational level of the parents are included. By using private and supplemental health insurance as additional 
TABLE 2: Descriptive statistics $(n=8713)$.

\begin{tabular}{|c|c|c|c|c|}
\hline Variable & Male & $N=4132$ & Female & $N=4581$ \\
\hline Varıable & & & & \\
\hline \multicolumn{5}{|l|}{ Endogenous variables } \\
\hline Smoker & 0.3192 & 0.4662 & 0.2552 & 0.4360 \\
\hline Alcohol & 0.2539 & 0.4353 & 0.0740 & 0.2618 \\
\hline Obesity & 0.1718 & 0.3773 & 0.1672 & 0.3732 \\
\hline Health & 0.5748 & 0.4944 & 0.5573 & 0.4968 \\
\hline \multicolumn{5}{|c|}{ Predisposing variables } \\
\hline Age $30-44$ & 0.3044 & 0.4602 & 0.2921 & 0.4548 \\
\hline Age 45-59 & 0.2561 & 0.4365 & 0.2611 & 0.4393 \\
\hline Age $60-74$ & 0.2236 & 0.4167 & 0.2059 & 0.4044 \\
\hline Age $>74$ & 0.0699 & 0.2551 & 0.0819 & 0.2742 \\
\hline Partnership & 0.7328 & 0.4425 & 0.6830 & 0.4653 \\
\hline Children & 0.2796 & 0.4488 & 0.2980 & 0.4574 \\
\hline Eastern Germany & 0.2851 & 0.4515 & 0.2796 & 0.4489 \\
\hline Turkey & 0.0346 & 0.1828 & 0.0273 & 0.1629 \\
\hline Rest of World & 0.0503 & 0.2187 & 0.0513 & 0.2206 \\
\hline \multicolumn{5}{|c|}{ Socioeconomic variables } \\
\hline Rel. poverty & 0.0833 & 0.2763 & 0.1067 & 0.3088 \\
\hline Tenous prosperity & 0.2101 & 0.4074 & 0.2438 & 0.4294 \\
\hline Higher income & 0.1007 & 0.3009 & 0.0902 & 0.2864 \\
\hline Rel. prosperity & 0.1416 & 0.3487 & 0.1135 & 0.3173 \\
\hline Economic worries & 0.2478 & 0.4318 & 0.2617 & 0.4396 \\
\hline Retired & 0.1963 & 0.3970 & 0.2065 & 0.4050 \\
\hline Unemployed & 0.0296 & 0.1693 & 0.0323 & 0.1768 \\
\hline Working h. 1-21 & 0.0194 & 0.1378 & 0.1155 & 0.3196 \\
\hline Working h. 22-42 & 0.2897 & 0.4537 & 0.2685 & 0.4432 \\
\hline Working h. $>42$ & 0.2916 & 0.4546 & 0.0967 & 0.2956 \\
\hline O-level & 0.2894 & 0.4536 & 0.3388 & 0.4734 \\
\hline High school & 0.1087 & 0.3113 & 0.1225 & 0.3279 \\
\hline University & 0.2140 & 0.4101 & 0.1570 & 0.3638 \\
\hline Education & 0.0748 & 0.2631 & 0.0849 & 0.2788 \\
\hline Private health ins. & 0.1498 & 0.3569 & 0.0819 & 0.2742 \\
\hline Supplemental ins. & 0.1130 & 0.3167 & 0.1377 & 0.3447 \\
\hline Risk averse & 0.2364 & 0.4250 & 0.3558 & 0.4788 \\
\hline Risk taker & 0.2962 & 0.4566 & 0.1814 & 0.3854 \\
\hline Renovation & 0.2773 & 0.4477 & 0.2794 & 0.4488 \\
\hline Mother O-level & 0.2270 & 0.4189 & 0.2441 & 0.4296 \\
\hline Father O-level & 0.2556 & 0.4362 & 0.2657 & 0.4417 \\
\hline
\end{tabular}

explaining variables we can account for differences in moral hazard effects of different types of health insurance [33].

If one takes a look at the descriptive statistics in Table 2, it is obvious that there are gender differences with respect to health-related behaviour. In detail, 6 percent more men than women are currently smokers. 25.39 percent of males respond that they drink alcohol regularly, but only 7.4 percent of females. The prevalence of obesity is not significantly different between both sexes. ${ }^{7} 57.48$ and 55.73 percent range their health above average.
TABLE 3: Shares of respondents drinking, smoking or being obese (in percent).

\begin{tabular}{lcccc}
\hline & \multicolumn{4}{c}{ Male } \\
\hline & $\begin{array}{c}\text { Nonsmoker } \\
\text { Not obese }\end{array}$ & Obese & Not obese & Obese \\
\hline Drinks alcohol not regularly & 42,06 & 9,56 & 19,89 & 3,10 \\
Regular alcohol consumption & 13,38 & 3,07 & 7,48 & 1,45 \\
\hline \multicolumn{4}{c}{ Female } \\
\hline & Nonsmoker & Smoker \\
& Not obese & Obese & Not obese & Obese \\
Drinks alcohol not regularly & 56,69 & 12,57 & 19,84 & 3,49 \\
Regular alcohol consumption & 4,78 & 0,44 & 1,96 & 0,22 \\
\hline
\end{tabular}

Given the assumption that negative health consequences are driven by the quantity of adverse health behaviours, it is of interest how many respondents behave entirely healthy or unhealthy (see Table 3).

Here, data shows again major differences between males and females. While 56.69 percent of females are without any adverse behaviour, only 42.06 percent of males behave entirely healthy. Moreover, only 0.22 percent of women state that they are frequent drinkers, smokers, and obese while this is true for 1.45 percent of men.

\section{Estimation Method}

4.1. Reporting Heterogeneity and Health Capital Stock. Selfreported measures of health and their validity have caused a considerable debate $[11,34]$. The self-assessed health variable might be vulnerable to a reporting bias because of anticipation and measurement heterogeneity $[35,36]$. The original health variable in the dataset $(\mathrm{SAH})$ is a five-point scale variable ranging from very good to bad. To correct for possible reporting heterogeneity, we apply a technique proposed by Disney et al. [37]. We estimate a model of selfassessed health as a function of objective health measures $m$, for example, the utilisation of health care or physical and mental well-being as well as personal characteristics $x$ like age and education [37]. First, we can write the unobservable health status as a function of $x$ and $m$ and unobservables $u_{i t}$ :

$$
\eta_{i t}=x_{i t}^{\prime} \beta+m_{i t}^{\prime} \gamma+u_{i t}
$$

Instead of $\eta_{i t}$, the categorical variable self-assessed health $h_{i t}$ is observed in the data set. This variable may be measured with a reporting error since the assessment of health may depend on age, education, and health problems. Hence, the latent health stock $h_{i t}^{*}$ as the counterpart of the observed selfassessed health is a function of the unobservable health status $\eta_{i t}$ and a reporting error $\varepsilon_{i t}:{ }^{8}$

$$
h_{i t}^{*}=\eta_{i t}+\varepsilon_{i t} .
$$

The latent health variable can be linked to the categorical indicator $h_{i t}$ using the following observation mechanism:

$$
h_{i t}=j, \quad \text { if } \mu_{j-1}<h_{i t}^{*}<\mu_{j}, j=1, \ldots, 5 \text {. }
$$


TABLE 4: Descriptive statistics health variables.

\begin{tabular}{lcccc}
\hline & \multicolumn{2}{c}{ Male } & \multicolumn{2}{c}{ Female } \\
Additional variables & Mean & Std. Dev. & Min & Max \\
\hline SAH & 2.6268 & 0.9472 & 2.7108 & 0.9585 \\
Handicap & 0.1428 & 0.3499 & 0.1166 & 0.3209 \\
Hospital & 0.1067 & 0.3088 & 0.1369 & 0.3437 \\
1-2 doctor visits & 0.3548 & 0.4785 & 0.3707 & 0.4830 \\
3-4 doctor visits & 0.1517 & 0.3588 & 0.2056 & 0.4042 \\
At least 5 doctor visits & 0.1251 & 0.3309 & 0.1777 & 0.3823 \\
Physical functioning & 50.2097 & 9.9242 & 48.5586 & 10.4497 \\
Role physical & 50.4936 & 9.8977 & 48.4472 & 10.3399 \\
Bodily pain & 50.2161 & 9.8383 & 48.7392 & 10.4457 \\
Vitality & 50.3684 & 9.7242 & 48.7319 & 10.0824 \\
Social functioning & 50.3707 & 9.8357 & 48.7376 & 10.6430 \\
Role emotional & 50.6225 & 9.5372 & 48.5711 & 10.5158 \\
Mental health & 51.2436 & 10.0891 & 48.6149 & 10.1642 \\
\hline
\end{tabular}

Equation (3) shows that our observable health variable takes the value $j$ if the latent health stock lies between the two thresholds $\mu_{j-1}$ and $\mu_{j}$. Combining this observation mechanism with (1), the model can be estimated using ordered probit techniques. Using the predicted values, we can normalise the health stock using a $z$-transformation. This yields a health capital stock with a zero mean and a constant variance of one. Furthermore, positive values of our health capital stock variable indicate that the respondent's health is above the sample mean in this period.

In the estimation at hand, we use the variables physical functioning, role physical, bodily pain, vitality, social functioning, role emotional, and mental health. These are elements of the SF-12v2 indicators mentioned above (for a detailed description see [31]). The descriptive statistics are shown in Table 4 . Table 5 refers to the estimation results.

These results presented in Table 5 are then used to calculate the health capital stock as a linear prediction. Together with the estimated cut-points, this prediction is taken to generate a new self-assessed health variable.

4.2. The Multivariate Probit Model. Our estimation approach reflects the simultaneity of health behaviours and their impact on health. The multivariate probit model can be seen as a generalization of the bivariate probit model presented in Maddala [38]. In our specific case, the model consists of three reduced-form equations and one structural equation. ${ }^{9}$ The main advantage of estimating four single probit models is that it accounts for possible endogeneity of health behaviours in the structural equation through the recursive structure:

$$
\begin{aligned}
& y_{1 i}^{*}=\beta_{1}^{\prime} X_{1 i}+\varepsilon_{1 i}, \\
& y_{2 i}^{*}=\beta_{2}^{\prime} X_{2 i}+\varepsilon_{2 i}, \\
& y_{3 i}^{*}=\beta_{3}^{\prime} X_{3 i}+\varepsilon_{3 i}, \\
& y_{4 i}^{*}=\delta_{41} y_{1 i}+\delta_{42} y_{2 i}+\delta_{43} y_{3 i}+\beta_{4}^{\prime} X_{4 i}+\varepsilon_{4 i} .
\end{aligned}
$$

\begin{tabular}{|c|c|c|c|c|}
\hline \multirow[b]{2}{*}{ Age 30-44 } & \multicolumn{2}{|c|}{ Male } & \multicolumn{2}{|c|}{ Female } \\
\hline & $0.2977^{* * *}$ & $(0.000)$ & $0.2592^{* * *}$ & $(0.000)$ \\
\hline Age $45-59$ & $0.6679 * * *$ & $(0.000)$ & $0.5649^{* * *}$ & $(0.000)$ \\
\hline Age $60-74$ & $0.6214^{* * *}$ & $(0.000)$ & $0.6162^{* * *}$ & $(0.000)$ \\
\hline Age $>74$ & $0.4751^{* * *}$ & $(0.000)$ & $0.5444^{* * *}$ & $(0.000)$ \\
\hline O-level & -0.0256 & $(0.570)$ & -0.0683 & $(0.110)$ \\
\hline High school & -0.0746 & $(0.248)$ & -0.0463 & $(0.445)$ \\
\hline University & $-0.1379 * * *$ & $(0.005)$ & $-0.1018^{* *}$ & $(0.047)$ \\
\hline Handicap & $0.3194^{* * *}$ & $(0.000)$ & $0.2277^{* * *}$ & $(0.000)$ \\
\hline Hospital & $0.2024^{* * *}$ & $(0.002)$ & $0.1012^{*}$ & $(0.058)$ \\
\hline 1-2 doctor visits & $0.2143^{* * *}$ & $(0.000)$ & $0.2030^{* * *}$ & $(0.000)$ \\
\hline 3-4 doctor visits & $0.4321^{* * *}$ & $(0.000)$ & $0.4303^{* * *}$ & $(0.000)$ \\
\hline At least 5 doctor visits & $0.6511^{* * *}$ & $(0.000)$ & $0.5697^{* * *}$ & $(0.000)$ \\
\hline Physical functioning & $-0.0388^{* * *}$ & $(0.000)$ & $-0.0389 * * *$ & $(0.000)$ \\
\hline Role physical & $-0.0189^{* * *}$ & $(0.000)$ & $-0.0207^{* * *}$ & $(0.000)$ \\
\hline Bodily pain & $-0.0314^{* * *}$ & $(0.000)$ & $-0.0301^{* * *}$ & $(0.000)$ \\
\hline Vitality & $-0.0256^{* * *}$ & $(0.000)$ & $-0.0191^{* * *}$ & $(0.000)$ \\
\hline Social functioning & $-0.0086^{* * *}$ & $(0.003)$ & $-0.0056^{* *}$ & $(0.026)$ \\
\hline Role emotional & -0.0012 & $(0.686)$ & 0.0004 & $(0.886)$ \\
\hline Mental health & $-0.0094^{* * *}$ & $(0.000)$ & $-0.0153^{* * *}$ & $(0.000)$ \\
\hline $\mathrm{N}$ & 4132 & & 4581 & \\
\hline AIC & 7606.4021 & & 8675.2875 & \\
\hline $\mathrm{BIC}$ & 7751.9120 & & 8823.1699 & \\
\hline $\begin{array}{l}\text { Log } \\
\text { pseudo-Likelihood }\end{array}$ & -3780.2011 & & -4314.6437 & \\
\hline Wald test $\left(\chi^{2}(28)\right)$ & $2267.40^{* * *}$ & & $2504.58^{* * *}$ & \\
\hline Pseudo $\mathrm{R}^{2}$ & 0.3106 & & 0.3034 & \\
\hline
\end{tabular}

TABLE 5: Estimation results self-assessed health.

$P$-values in parentheses; ${ }^{*} P<0.1,{ }^{* *} P<0.05,{ }^{* * *} P<0.01$.

Here, we have $m=1, \ldots, 4$ equations and $i=1, \ldots, N$ observations. $X_{m i}$ are vectors of exogenous variables, $\beta_{m}$ the associated parameter vectors, and $\varepsilon_{1 i}, \ldots, \varepsilon_{M i}$ are normally distributed errors with a constant variance var $\left(\varepsilon_{m i}\right)=1$. Given the production of health, we identify two classes of binary-dependent variables: first, health behaviour of the individual, and second, our corrected measure of selfassessed health. The recursive structure of the multivariate probit represents the distinction between the dependent variables as follows. The equations for the health behaviour variables are reduced-form equations. The health equation is a structural equation with the health behaviour variables as explanatory factors.

The covariance between the error terms of equations $j$ and $k$ can be expressed as correlations $\rho_{j k}=\rho_{k j}$ [39]. They measure in how far unobserved factors influence health relevant behaviour and health simultaneously. All equations in (4) can be estimated separately as single probit models but the estimated coefficients would be inefficient because the correlation between the error terms is neglected. Only in the case of independent error terms $\varepsilon_{m i}$ (all $\rho$ are not significantly different from zero) it is possible to deal with the above model as independent equations [38]. ${ }^{10}$ 
TABLE 6: Comparison of additional exclusion restrictions for the health equation.

\begin{tabular}{lcccc}
\hline \multicolumn{2}{c}{ Male } & \multicolumn{2}{c}{ Female } \\
\hline & With exclusion restrictions & Without exclusion restrictions & With exclusion restrictions & Without exclusion restrictions \\
\hline AIC & 17432.60 & 17431.36 & 15825.38 & 15827.39 \\
BIC & 18261.38 & 18272.79 & 16667.66 & 16682.53 \\
Likelihood & -8585.301 & -8582.680 & -7781.688 & -7780.693 \\
LR-Test & $5.2420(0.073)$ & $\mathrm{Chi}^{2}(2, \alpha=0.05)=5.99$ & $1.9899(0.370)$ & $\mathrm{Chi}^{2}(2, \alpha=0.05)=5.99$ \\
\hline
\end{tabular}

4.3. Model Identification. The estimation of a recursive multivariate probit model requires further assumptions for the identification of the model parameters. For the model given in (4), Maddala [38] shows that the number of parameters to be estimated is larger than the number of probabilities using a constant only model. In this case, the parameters in the structural equation are not identified. To answer this problem, Maddala proposes that at least one of the reducedform exogenous variables must not be included in the structural equation as explanatory variable. On the contrary, the structural equations may contain variables not included in the reduced-form equations. In contrast to this and according to Wilde [40], the parameters of the model are identified as long as there is at least one varying exogenous regressor.

In our approach, we impose exclusion restrictions and test their validity. For the reduced form equations, we use the complete set of predisposing and socioeconomic variables. In the health equation, we hypothesize that parental education is without influence on health assessment and is therefore excluded.

For the selection of the appropriate set of exclusion restrictions, measures of goodness-of-fit are used. First, the Akaike information criterion (AIC) and, second, the Bayesian information criterion (BIC) are employed [41]. The results for the information criteria for the two specifications are presented in Table 6 . For both subsamples, the information criteria of the Maddala and the Wilde approach are relatively close to each other. Regarding the female sample, both AIC and BIC are lower when estimating without parental education as explanatory variables in the health equation. In contrast to this, for males only the BIC prefers the restricted setting. This is confirmed by the result of a likelihood ratio test for both samples at the 5 percent level.

\section{Estimation Results}

The results indicate that behaviour is determined through different impact factors for males and females (see Tables 7 and 8). Concerning the income variables, for females relative poverty leads to a higher probability of being a smoker or being obese, while relative prosperity lowers the likelihood of obesity. In addition, relative prosperity goes along with frequent alcohol consumption. Last, smoking is positively related to strong economic worries. For males, only a positive relationship between relative poverty and smoking can be found, while relative prosperity again goes along with a higher probability of drinking alcohol regularly. In the obesity equation, there are no direct income effects for men. In contrast to female behaviour, males who state strong economic worries tend to drink alcohol less often but there exists a positive relationship with smoking and obesity. Income effects are thus not comparable across different health behaviours. While we find a distinct impact of low income on the probability of smoking, frequent drinking seems to be more prominent among high-income earners. For obesity, we find a negative impact of higher income and a positive impact of poverty. While peer-group effects may be the reason for the first two findings, the impact of income on body weight may reflect differences in the distribution of knowledge and food prices.

Theory suggests that being in the labour force goes along with higher opportunity costs of adverse health behaviour in terms of lower productivity, illness, and related costs or simply time costs when physician visits are necessary. ${ }^{11}$ Therefore, a positive relationship between moderate working hours and behaviour was expected for both sexes, while long working hours may lead to alcohol or tobacco consumption to cope with stress. Surprisingly, no such effect can be found in the equations for males. Here, only being unemployed is positively related to smoking and drinking. In contrast, there exist strong labour force effects for women. In general, women who work tend to smoke and drink alcohol more often but are obese less frequently. Being unemployed raises the probability of smoking but has no effect on alcohol consumption and obesity. Interestingly, retired females have a lower probability of smoking compared to those who are not in the labour force but males who are retired smoke and drink alcohol more often.

Regarding education effects, there are only minor differences between males and females, but results are again somewhat surprising. First and as expected, education reduces tobacco consumption and excessive body weight. Second and against our expectations, the probability of drinking alcohol rises with the educational status. This may be because of a higher social acceptance of drinking wine, for instance [42].

Given these key effects on health relevant behaviour, it is of interest which factors are the main determinants of health. Results show that for males, drinking alcohol and obesity are of negative impact on health, while smoking is without any significant effect, a result similar to [29]. Furthermore, health is positively influenced by a high relative income position and by being in the labour force. Except for men with a university degree, education is without any impact on health. For females, results are different again. Here, drinking influences health assessment positively but being obese is not relevant. While being in the labour force is again related to 


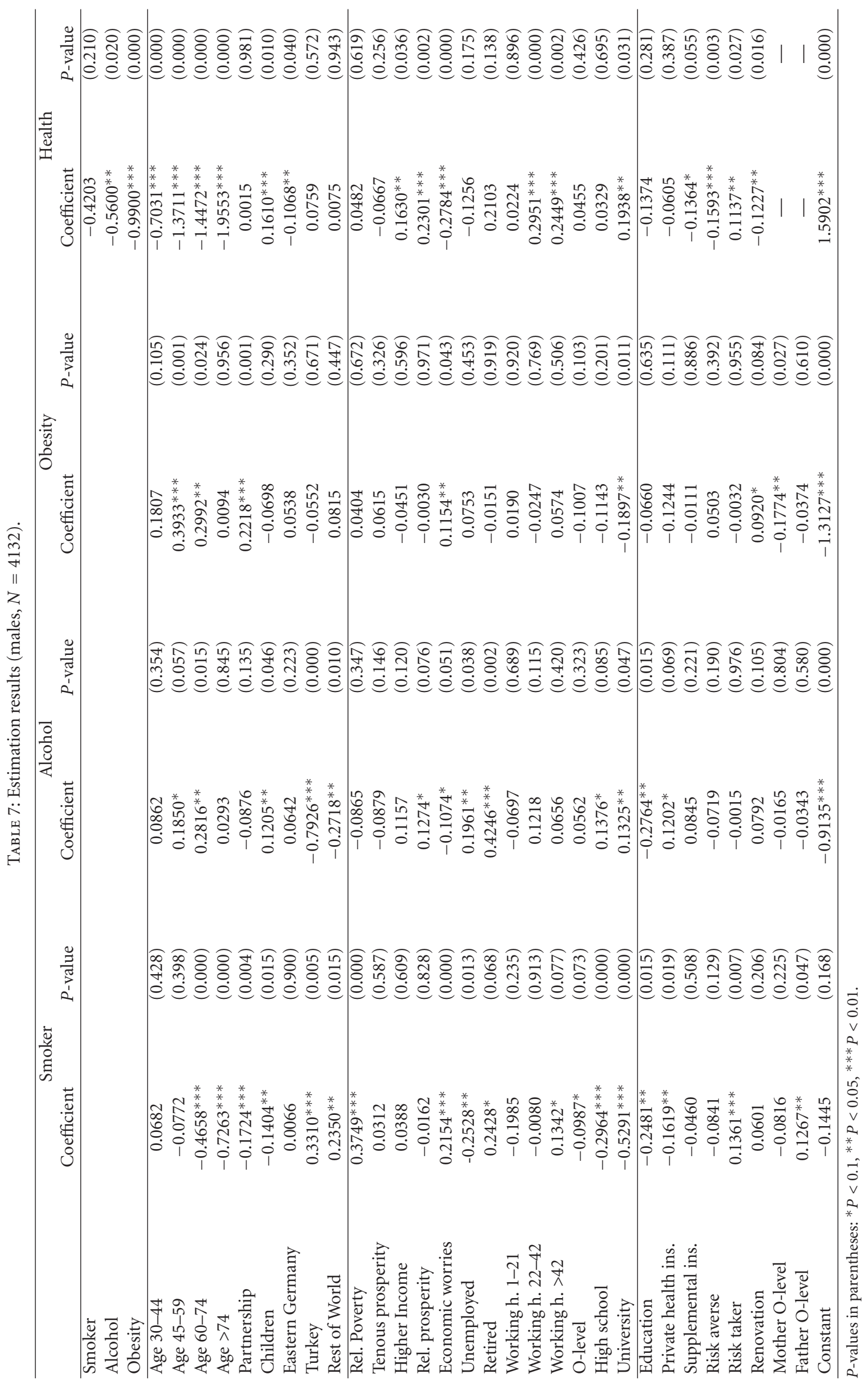







TABLE 9: Correlation coefficients.

\begin{tabular}{|c|c|c|c|}
\hline \multicolumn{4}{|c|}{ Males } \\
\hline \multirow{3}{*}{ Correlation coefficients } & rho $21=0.1403^{* * *}$ & & \\
\hline & $\operatorname{rho} 31=-0.1099^{* * *}$ & rho32 $=0.0183$ & \\
\hline & rho41 $=0.2163$ & rho42 $=0.3535^{* *}$ & rho43 $=0.3923^{* * *}$ \\
\hline LR-Test Chi $^{2}(5)$ & $45.2277^{* * *}$ & & \\
\hline AIC & 17432.6021 & & \\
\hline $\mathrm{BIC}$ & 18261.3758 & & \\
\hline \multicolumn{4}{|c|}{ Females } \\
\hline \multirow{3}{*}{ Correlation coefficients } & rho2 $1=0.1068^{* * *}$ & & \\
\hline & rho31 $=-0.0490$ & rho32 $=-0.1531^{* * *}$ & \\
\hline & rho41 $=-0.0382$ & rho42 $=-0.2803$ & $\operatorname{rho} 43=-0.0351$ \\
\hline LR-Test Chi $^{2}(5)$ & $21.5408^{* * *}$ & & \\
\hline AIC & 15825.3759 & & \\
\hline $\mathrm{BIC}$ & 16667.6630 & & \\
\hline
\end{tabular}

a high probability of good health, income is without any impact for women. Last, strong positive effects for education can be found.

Concerning the estimation technique, the main advantage of the multivariate probit model is that it considers possible dependencies between the equations. Therefore, it is possible to test whether health behaviour is endogenous for health. The four estimated equations involve six correlation coefficients $\rho_{j k}$ which measure the pairwise correlation between the three health relevant behaviour indicators and the health variable. Four of the correlation coefficients are of significance for males and two for females (see Table 9). A positive correlation means that unobserved factors influence both variables in the same direction. We find a positive correlation between smoking and alcohol for both men and women. This implies that there exist factors not in our data like enjoyment that result in a higher probability of smoking and drinking. On contrary, we find a negative correlation between smoking and obesity for men. For women, alcohol and obesity are negatively correlated. One fundamental difference is that the correlation between health and alcohol is positive for men and negative for women. On the other hand, the partial effect of alcohol on health is positive for women and negative for men. ${ }^{12}$ Last, we find a positive correlation between the health and obesity equation. The null hypothesis of no joint significance of these parameters is rejected using a likelihood ratio test. These results imply that the equations are not stochastically independent and that single probit estimates would have led to inefficient standard errors. Moreover, the dependent variables of the first three equations can be treated as endogenous in the health equation.

\section{Conclusion and Policy Implications}

In our analysis, health production is viewed as a process that can be separated into health behavioural aspects and health. From a theoretical point of view, the importance of the individual's health behaviour for the health production process is beyond controversy. To test for the determinants of health behaviour and self-assessed health, we apply a multivariate probit approach consisting of three reduced form equations and one structural equation. By using this procedure, it is possible to account for the endogeneity of smoking, alcohol consumption and obesity for health. In addition, as reporting heterogeneity is a problem when using self-assessed data on health, we correct this heterogeneity by estimating reported health on age, education, health care utilisation, and objective health indicators.

Estimation shows that health behaviours as well as their consequences on health are gender-specific. To sum up our findings, income including economic worries, labour force participation, and education are the main socioeconomic determinants of behaviour but differ in direction and strength. For males, we find that alcohol consumption and obesity negatively determine the assessment of health while for women a positive relation between alcohol and health is present.

Concerning policy implications, men and women with higher education tend to smoke less than individuals without graduation. Furthermore, a university degree has a negative influence on obesity for both sexes. This implies that education is a key factor and that information campaigns about the hazardous health consequences of smoking and heavy body weight may help to reduce their prevalence especially for people with lower education. In contrast to this, better educated individuals have a higher probability of drinking alcohol regularly. These results indicate that for alcohol consumption a lack of information does not exist. One possible explanation is the existence of peer group or bandwagon effects, which go along with the social acceptance of drinking.

Second and only for females, working hours are of main importance for health relevant behaviour. In detail, women in the labour force tend to be smokers more often, which is again due to peer group effects. Furthermore, smoking as well as drinking alcohol may be consequences of a high stress level. In contrast, women who work less than 42 hours a week are significantly less obese, indicating that this group faces higher opportunity costs of absence from work due to heavy body weight-related illnesses. In addition, obesity may 
increase the risk of bullying at work especially for women. Andreyeva [43] points out that unemployment increases the risk of obesity. In our estimations, no unemployment effects can be found compared to those who do not work because of being a housewife or other reasons; nevertheless, due to strong negative effects of working hours on excessive body weight, getting women in the labour force may be another way to reduce the prevalence of obesity.

Third, both education and labour force participation are main determinants of labour income, which is a principal component of family household net income. Estimation shows that relative poverty is an important impact factor for tobacco consumption, while drinking alcohol is positively influenced by a high socioeconomic status. In addition, higher income lowers the probability of being obese for women. For men, the income position is without any effect on heavy body weight.

The dependence of smoking on socioeconomic status raises the question of financial incentives to induce healthy behaviours. Rising taxes on tobacco may lower consumption, given a negative price elasticity of smoking [42]. In Germany, taxation of alcoholic mixed drinks in 2004 in combination with a prohibition of sale for underage individuals led to a significantly decrease in consumption. According to our estimation results, especially high-income individuals tend to drink even more than those in middle-income positions. Therefore, higher taxes are unlikely to reduce drinking significantly for the group in relative prosperity.

Regarding policy implications from the results on health behaviour one has to take different effects for males and females into account. Alcohol and obesity both reduce the reported health status for males. For women, only a positive effect of drinking on health can be found. The difference in the effects of alcohol consumption may be due to an unobserved level effect and the J-shape argument of drinking. First, it seems probable that there exist differences in the real amount of alcohol intake depending on the interpretation of drinking frequencies. Second, the J-shape argument indicates that regular but moderate drinking of wine and beer goes along with positive health consequences or psychic wellbeing as part of the health status, compared to those who are abstainers or heavy drinkers [44].

For both sexes, smoking is without any significant health effect. First, there seems to be no difference in the valuation of health between smokers and nonsmokers. Second, individuals face the consequences of their behaviour later in life and not in direct relation to their actions. Moreover, the probability of being a smoker lowers with age. Therefore, health problems may arise after quitting smoking. At present, politics aims at reducing smoking through information campaigns as well as a ban from working places or restaurants. Due to a higher probability for low-income individuals, higher taxes may also be an appropriate means. Concerning obesity, it seems that high-calorie intake is not primarily a question of income but a question of education. Further information about the ingredients and the nutritional value of convenience food may be one key to reduce the prevalence of obesity given that individuals have the capabilities to deal with this information.

\section{Acknowledgments}

The authors would like to thank Andrew Jones, Nigel Rice, Volker Ulrich, and two anonymous referees for helpful comments on this paper-of course, any remaining mistakes are entirely the authors errors.

\section{Endnotes}

1. High body weight and obesity are measured by Body Mass Index (BMI), calculated as weight in kilograms divided by height in meters squared. Obesity means a BMI of 30 or greater. For being overweight, the BMI ranges between a value of 25 and 29.9 (see [30] for a classification in more detail).

2. As we use German microdata one might argue that income loss due to illness and therefore opportunity costs are relatively small because of a comprehensive sick pay system in Germany. As smoking and drinking as well as obesity mostly go along with chronic health conditions rather than acute illness, sick leaves are often not short period. For illnesses lasting more than six weeks sick pays are reduced, resulting in income losses. Moreover, chances for further promotion and therefore higher earned income decline.

3. The data used in this publication were made available to us by the German Socio-Economic Panel Study (SOEP) at the German Institute for Economic Research (DIW), Berlin. Although the Socio-Economic Panel is a representative dataset in general, in our sample Eastern Germans are overrepresented due to nonresponses and drop outs. Concerning the insurance status, the fraction of fully privately insured corresponds to the actual level in Germany. Taking into account that Eastern Germans are overrepresented in this dataset and that their earned income is below average, the share of fully private insured might be slightly biased upwards.

4. Similar indicators are used by Vita et al. [45]. They show that mortality rates and disability risks depend on tobacco consumption, physical exercises, and nutrition.

5. The SF-12v2 is a health-related questionnaire especially on aspects of quality of life covering the dimensions physical and mental health [31].

6. In an alternative setting, we also included variables for the occupational status, for example, whether a respondent is white or blue collar worker, self-employed, or employed in the public sector. In this specification, working time effects cannot be identified and separated from occupational status. Hence, we use the restricted setting with working time effects only.

7. Sturm [5] mentions that weight is often underreported in interviewer-based surveys while height is overreported. Although our data corresponds with data from the German Federal Statistical Office, it may be that the prevalence of obesity is even higher.

8. Disney et al. [37] assume that the error terms in (1) and (2) are uncorrelated. 
9. Balia and Jones [29] transform the categorical variable self-assessed health into a binary indicator that takes value 1 if individual-perceived health is excellent or good, and 0 if it is fair or poor.

10. Knapp and Seaks [46] provide a Hausman test for the exogeneity of a dummy variable in a probit model, which is based on the estimated correlation coefficients.

11. For the highest two age groups (age 60 and above), the labour force participation is significantly lower than for the other age groups. While about 65 percent of the respondents younger than 60 are working at least part time, the share drops to 6.5 percent for those aged 60 and above.

12. Here, large differences in the intake of alcohol as well as in the perception of regular drinking might cause such an effect.

\section{References}

[1] J. Cawley and C. Ruhm, The Economics of Risky Health Behaviors. Working Paper 17081, National Bureau of Economic Research, Cambridge, Mass, USA, 2011.

[2] U.S. Department of Health and Human Services, The Health Consequences of Smoking: A Report of the Surgeon General, U.S. Department of Health and Human Services, Centers for Disease Control and Prevention, National Center for Chronic Disease Prevention and Health Promotion, Office on Smoking and Health, Atlanta, Ga, USA, 2004.

[3] J. Rehm, G. Gmel, C. T. Sempos, and M. Trevisan, "Alcoholrelated morbidity and mortality," Alcohol Research and Health, vol. 27, no. 1, pp. 39-51, 2003.

[4] WHO/World Health Organization, "The Challenge of Obesity in the WHO European Region," Fact sheet EURO/13/05, 2005.

[5] R. Sturm, "The effects of obesity, smoking, and drinking on medical problems and costs," Health Affairs, vol. 21, no. 2, pp. 245-253, 2002.

[6] H. Harwood, Updating Estimates of the Economic Costs of Alcohol Abuse in the United States: EstimatesMethods, and Data. Report prepared by The Lewin Group for the National Institute on Alcohol Abuse and Alcoholism, Update Based on estimates, analyses, and data report. NIH Publication No. 98-4327. Rockville, Md, USA: National Institutes of Health, 1998, National Institutes of Health, Department of Health and Human Services 2000.

[7] E. A. Finkelstein, J. G. Trogdon, J. W. Cohen, and W. Dietz, "Annual medical spending attributable to obesity: payer-and service-specific estimates," Health Affairs, vol. 28, no. 5, pp. w822-w831, 2009.

[8] S. Neubauer, R. Welte, A. Beiche, H. König, K. Büsch, and R. Leidl, "Mortality, morbidity and costs attributable to smoking in Germany: update and a 10-year comparision," Tobacco Control, vol. 15, pp. 464-471, 2006.

[9] A. Konnopka and H. H. König, "Direct and indirect costs attributable to alcohol consumption in Germany," PharmacoEconomics, vol. 25, no. 7, pp. 605-618, 2007.

[10] A. Konnopka, M. Bödemann, and H. H. König, "Health burden and costs of obesity and overweight in Germany," European Journal of Health Economics, vol. 12, pp. 345-352, 2011.

[11] U. Schneider, C. Pfarr, B. S. Schneider, and V. Ulrich, "I feel good! gender differences and reporting heterogeneity in self-assessed health," European Journal of Health Economics. In press.

[12] M. Grossman, "On the concept of health capital and the demand for health," Journal of Political Economy, vol. 80, pp. 223-255, 1972.

[13] P. M. Krueger and V. W. Chang, "Being poor and coping with stress: health behaviors and the risk of death," American Journal of Public Health, vol. 98, no. 5, pp. 889-896, 2008.

[14] M. J. Moore and J. W. Hughes, "The health care consequences of smoking and its regulation," Forum for Health Economics and Policy, vol. 4, pp. 31-70, 2001.

[15] W. Thefeld, "Verbreitung der Herz-Kreislauf-Risikofaktoren Hypercholesterinämie, Hypertonie und Rauchen in der Bevölkerung," Bundesgesundheitsblatt, vol. 43, pp. 415-423, 2000.

[16] E. Conduit, A. Appels, and A. Lewis, "Cardioprotective effect of moderate drinking: possible mediation by vital exhaustion," Alcohol and Alcoholism, vol. 33, no. 5, pp. 528-532, 1998.

[17] A. Di Castelnuovo, S. Costanzo, V. Bagnardi, M. B. Donati, L. Iacoviello, and G. De Gaetano, "Alcohol dosing and total mortality in men and women: an updated meta-analysis of 34 prospective studies," Archives of Internal Medicine, vol. 166, no. 22, pp. 2437-2445, 2006.

[18] D. S. Kenkel, "Health behavior, health knowledge, and schooling," Journal of Political Economy, vol. 99, pp. 286-305, 1991.

[19] D. S. Kenkel, "Should you eat breakfast? Estimates from health production functions," Health Economics, vol. 4, no. 1, pp. 1529, 1995.

[20] J. P. Leigh, "Direct and indirect effects of education on health," Social Science and Medicine, vol. 17, no. 4, pp. 227-234, 1983.

[21] H. J. M. I. Kemna, "Working conditions and the relationship between schooling and health," Journal of Health Economics, vol. 6, no. 3, pp. 189-210, 1987.

[22] D. Schofield, The Impact of Employment and Hours of Work on Health Status and Health Service Use. Discussion Paper, NATSEM, Universtiy of Canberra 1996.

[23] M. Shields, "Long working hours and health," Perspectives on Labour and Income, vol. 12, no. 1, pp. 49-56, 2000.

[24] J. Bhattacharya, J. Currie, and S. Haider, "Poverty, food insecurity, and nutritional outcomes in children and adults," Journal of Health Economics, vol. 23, no. 4, pp. 839-862, 2004.

[25] D. B. Gilleskie and A. L. Harrison, "The effect of endogenous health inputs on the relationship between health and education," Economics of Education Review, vol. 17, no. 3, pp. 279297, 1998.

[26] B. S. Schneider, U. Schneider, and V. Ulrich, "Health and the decision to invest in education," Jahrbücher für Nationalökonomie und Statistik, vol. 227, no. 5-6, pp. 725-745, 2007.

[27] C. D. Mathers and D. J. Schofield, "The health consequences of unemployment: the evidence," Medical Journal of Australia, vol. 168, no. 4, pp. 178-182, 1998.

[28] S. J. Lin, "An analysis of lifestyles and health in Taiwan," Applied Economics Letters, vol. 15, no. 5, pp. 399-404, 2008.

[29] S. Balia and A. M. Jones, "Mortality, lifestyle and socioeconomic status," Journal of Health Economics, vol. 27, no. 1, pp. 1-26, 2008.

[30] WHO/World Health Organization, "Diet, Nutrition and the Prevention of Chronic Diseases. Report of a Joint WHO/FAO Expert Consultation," WHO Technical Report Series, 2003.

[31] H. H. Andersen, A. Mühlbacher, M. Nübling, J. Schupp, and G. Wagner, "Computation of standard values for physical and mental health scale scores using the SOEP version of SF-12v2," Schmollers Jahrbuch, vol. 127, pp. 171-182, 2007. 
[32] Statistisches Bundesamt, Gesellschaft Sozialwissenschaftlicher Infrastruktureinrichtungen; Wissenschaftszentrum Berlin für Sozialforschung, Datenreport 2008, Bundeszentrale für politische Bildung, Bonn, Germany, 2008.

[33] D. S. Kenkel, "Prevention," in Handbook of Health Economics, A. J. Culyer and J. P. Newhouse, Eds., vol. 1, pp. 1675-1720, Elsevier, Amsterdam, The Netherlands, 2000.

[34] A. M. Jones, "Panel data methods and applications to health econometrics," in Palgrave Handbook Palgrave Handbook of Econometrics. Volume 2: Applied Econometrics, T. Mills and K. Patterson, Eds., pp. 557-631, Palgrave MacMillan, London, UK, 2011.

[35] R. Hagan, A. M. Jones, and N. Rice, "Health shocks and the hazard rate of early retirement in the ECHP," Swiss Journal of Economics and Statistics, vol. 144, pp. 323-335, 2008.

[36] C. Hernández-Quevedo, A. M. Jones, and N. Rice, "Reporting Bias and Heterogeneity in Self-Assessed Health: Evidence from the British Household Panel Survey," HEDG Working Paper 05/04, University of York 2005.

[37] R. Disney, C. Emmerson, and M. Wakefield, "Ill health and retirement in Britain: a panel data-based analysis," Journal of Health Economics, vol. 25, no. 4, pp. 621-649, 2006.

[38] G. S. Maddala, Limited-Dependent and Qualitative Variables in Econometrics, Cambridge University Press, Cambridge, Mass, USA, 1983.

[39] L. Cappelari and S. P. Jenkins, "Multivariate probit regression using simulated maximum likelihood," Stata Journal, vol. 3, no. 3, pp. 278-294, 2003.

[40] J. Wilde, "Identification of multiple equation probit models with endogenous dummy regressors," Economics Letters, vol. 69, no. 3, pp. 309-312, 2000.

[41] J. S. Long, Regression Models for Categorical and Limited Dependent Variables, Sage, Thousand Oaks, Calif, USA, 1997.

[42] J. Cawley, "Reefer madness, Frank the tank, or pretty woman: to what extent do addictive behaviors respond to incentives?" in Incentives and Choices in Health Care, F. Sloan and H. Kasper, Eds., MIT Press, Cambridge, Mass, USA, 2008.

[43] T. Andreyeva, An International Comparison of Obesity in Older Adults: Effects and Risk Factors, RAND Corporation, Santa Monica, Calif, USA, 2006.

[44] K. J. Mukamal, S. E. Chiuve, and E. B. Rimm, "Alcohol consumption and risk for coronary heart disease in men with healthy lifestyles," Archives of Internal Medicine, vol. 166, no. 19, pp. 2145-2150, 2006.

[45] A. J. Vita, R. B. Terry, H. B. Hubert, and J. F. Fries, "Aging, health risks, and cumulative disability," New England Journal of Medicine, vol. 338, no. 15, pp. 1035-1041, 1998.

[46] L. G. Knapp and T. G. Seaks, "A Hausman test for a dummy variable in probit," Applied Economics Letters, vol. 5, no. 5, pp. 321-323, 1998. 


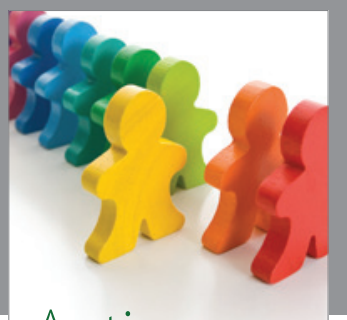

Autism

Research and Treatment
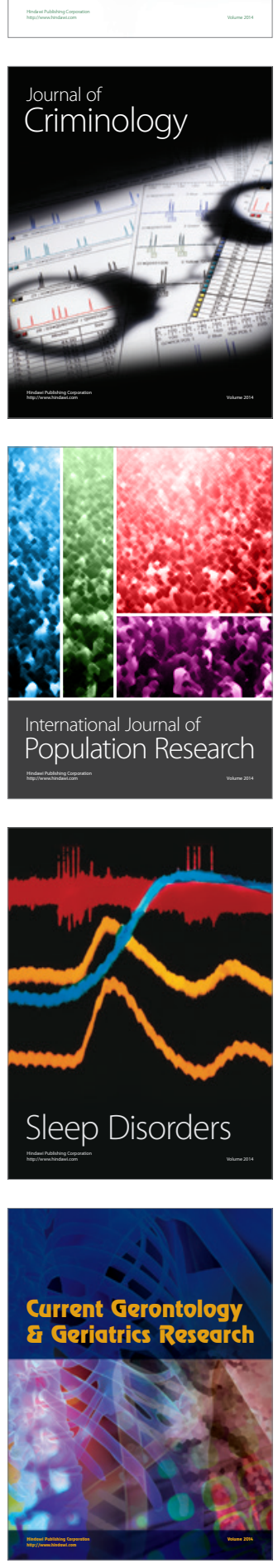
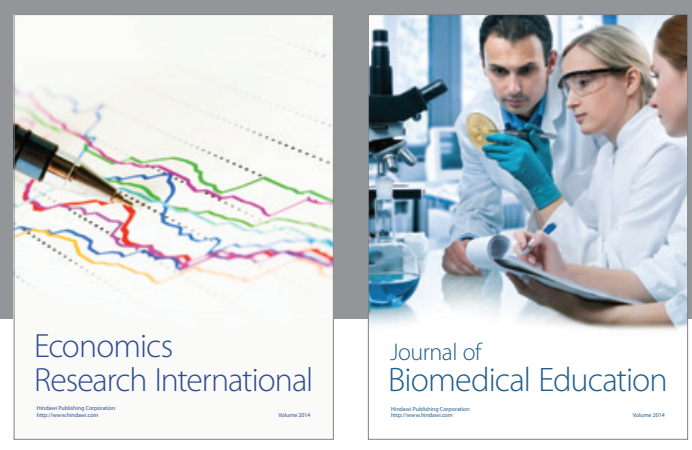

Journal of

Biomedical Education

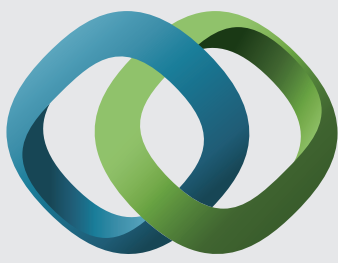

\section{Hindawi}

Submit your manuscripts at

http://www.hindawi.com
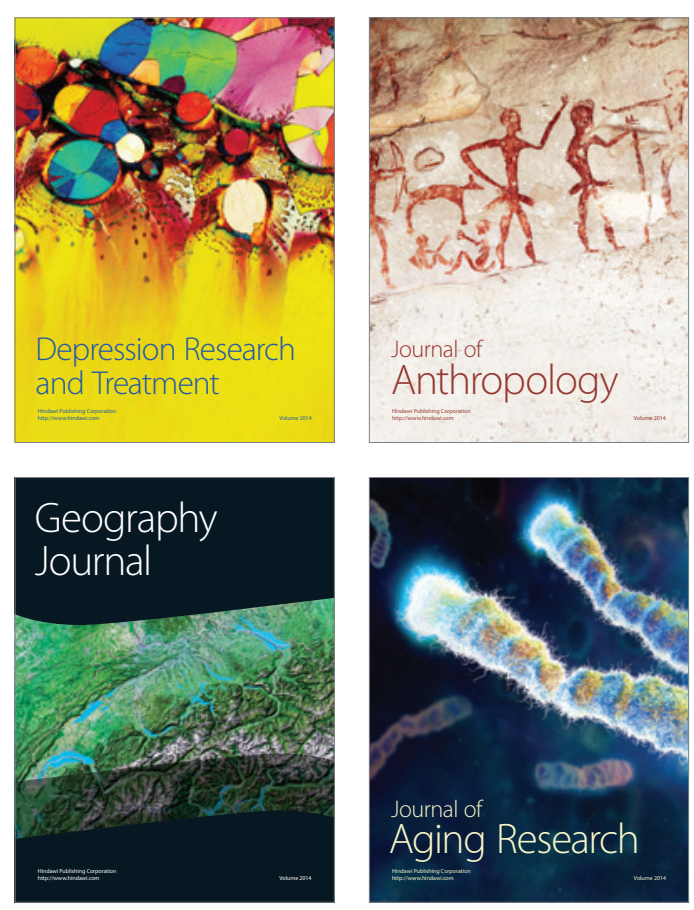



Nursing

Research and Practice



Child Development

Research

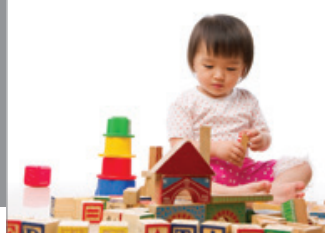

迥
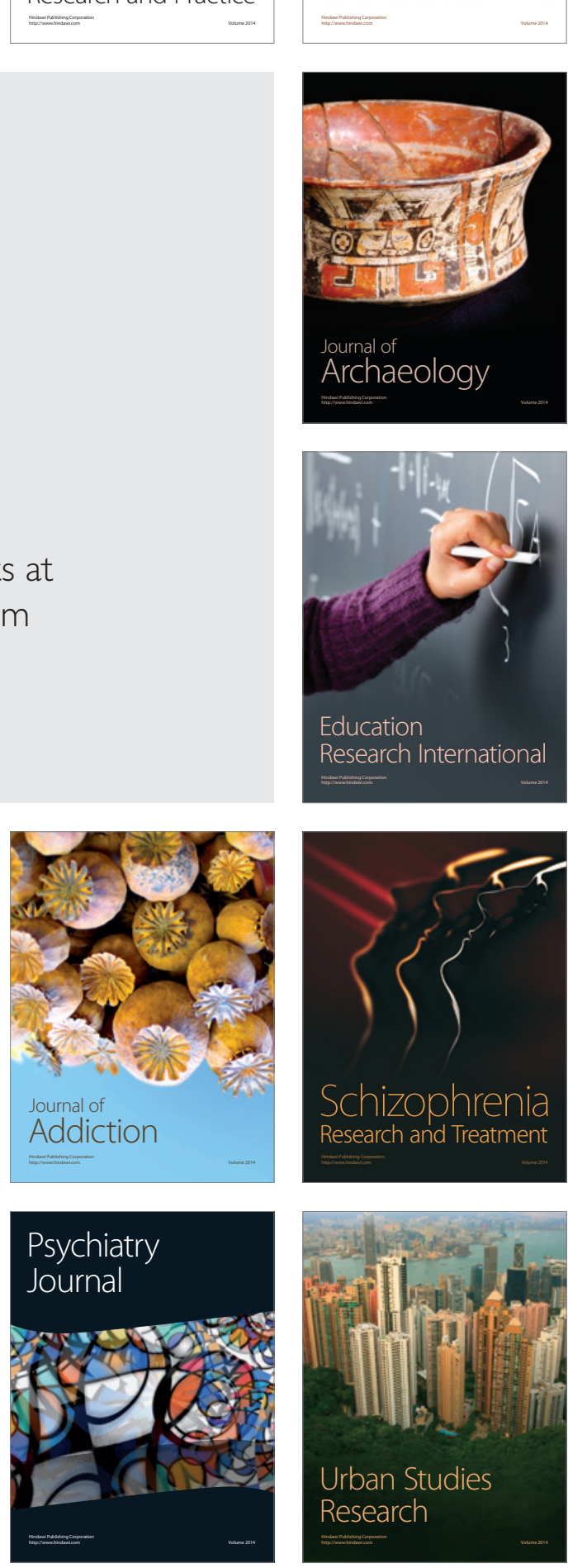